\title{
Tracking Drug Overdose Trends in Ohio using ED Chief Complaints
}

\author{
Alise L. Brown*, William E. Storm and Brian E. Fowler \\ Ohio Department of Health, Columbus, $\mathrm{OH}$, USA
}

\section{Objective}

Preliminary analysis was completed to define, identify, and track the trends of drug overdoses (OD), both intentional and unintentional, from emergency department (ED) and urgent care (UC) chief complaint data.

\section{Introduction}

The State of Ohio, as well as the country, has experienced an increasing incidence of drug ODs over the last three decades [3]. Of the increased number of unintended drug OD deaths in 2008, 9 out of 10 were caused by medications or illicit drugs [1]. In Ohio, drug ODs surpassed MVCs as the leading cause of injury death in 2007. This trend has continued through the most current available data [3]. Using chief complaint data to quickly track changes in the geographical distribution, demographics, and volume of drug ODs may aid public health efforts to decrease the number of associated deaths.

\section{Methods}

Chief complaint data from ED/UC visits were collected and analyzed from Ohio's syndromic surveillance application for 2010-2012. Ninety-six percent of all Ohio ED visits were captured during this timeframe. Due to the nonspecific nature of chief complaints as well as the lack of detail given upon registration at the $\mathrm{ED} / \mathrm{UC}$, attempting to separate visits into intentional vs. unintentional was not feasible. Therefore, a fairly specific classifier was created to define all potential ED/UC visits related to drug ODs. The data were analyzed, using SAS v 9.3, via time series analyses, and stratified by age, gender, and geographic region. Although these data types are pre-diagnostic in nature, they are more readily accessible than discharge data.

\section{Results}

On average, Ohio observed approx $66 \mathrm{ED} / \mathrm{UC}$ visits per day related to drug ODs from 2010-2012. The data show an increasing trend from 2010 through 2012 as well as a slight seasonal trend with higher visits observed in the spring/summer months as opposed to the autumn/winter months (Figure 1). The data showed that females attributed to a higher frequency of the drug ODs than males by approximately $4 \mathrm{ED} / \mathrm{UC}$ visits per day. Other data sources show a higher incidence in males than females related to unintentional drug ODs [3]. The highest age category attributing to the increase was the 18-39 years of age for both males and females, as shown in Figure 2. Population rates were calculated to identify those counties most affected by drug ODs. The data showed the highest rates of ED/UC visits related to drug ODs to be found in mostly rural areas of Ohio.

\section{Conclusions}

The annual death rate from unintentional drug poisonings by Ohio residents has increased from 3.6 in 2000 to 13.4 per 100,000 population in 2010[3]. As a result, the Ohio Governor created a Drug Abuse Task Force in 2009[4]. Ohio legislation (HB 93) implemented a prohibition on the operation of pain management clinics without a license on June 19, 2011[3]. According to this preliminary analysis, $\mathrm{ED} / \mathrm{UC}$ visits related to drug ODs 1 year post-implementation of $\mathrm{HB}$
93 continue to increase. It is unclear if HB 93 has slowed the rate of increase. Additionally, pre-diagnostic data has significant limitations including the significant possibility of misclassifying non-OD patient encounters as ODs. Further study of post-diagnostic data to confirm these trends is warranted.

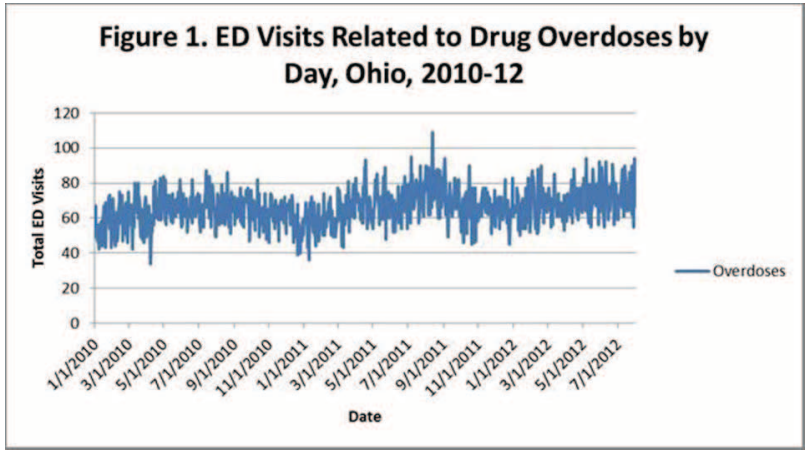

Figure 2. ED Visits Related to Drug Overdoses by Age Group, Ohio, 2010-12

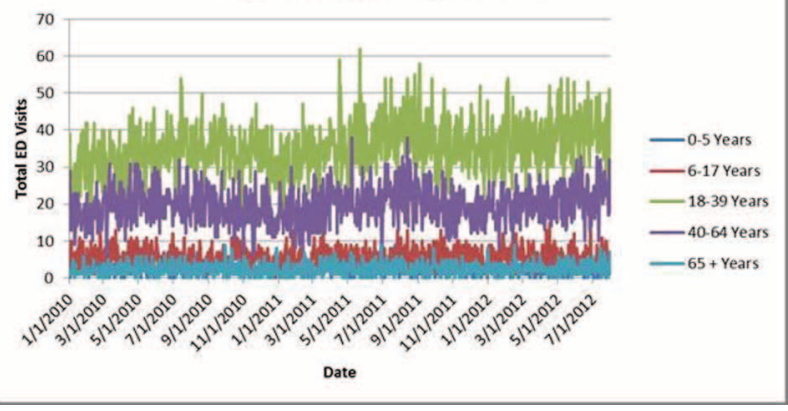

Keywords

Drug Overdose; Chief Complaints; prescription drug abuse

\section{References}

1. BM Kuehn. Poisonings Top Crashes for Injury-Related Deaths: JAMA. 2012;307(3):242-242. doi:10.1001/jama.2011.1998.

2. Ohio Department of Health. (July, 2012). Ohio's Opioid Epidemic: An Overview of the Problem. http://www.odh.ohio.gov/sitecore/content/HealthyOhio/default/vipp/data/rxdata.aspx

3. Ohio Injury Prevention Partnership, Prescription Drug Abuse Action Group. HB 93 Summary. http://www.ccbh.net/storage/prescriptionmeds/HB93Summary.pdf

4. Ohio Prescription Drug Abuse Task Force. Final report. http://www.odh.ohio.gov/ /media/ODH/ASSETS/Files/web\%20team /features/drug\%20overdose/opdatffinalreport.ashx

*Alise L. Brown

E-mail: alise.brown@odh.ohio.gov 